\title{
Simulation Study for TIG Welding of MONEL 400 and AISI 304
}

\author{
Jagwinderjit Singh Gill ${ }^{1 *}$, Charanjit Singh Kalra ${ }^{2}$ and Sukhwinder Singh Jolly ${ }^{3}$ \\ 1Sri Guru Granth Sahib World University, Fatehgarh Sahib - 140407, Punjab, India; jagwindergill23@gmail.com \\ 2Modern Manufacturers, Mohali - 160055, Punjab, India; cskalra9988@gmail.com \\ ${ }^{3}$ Mechanical Engineering, Sri Guru Granth Sahib World University, Fatehgarh Sahib - 140407, Punjab, India; \\ ssjolly2004@yahoo.co.in
}

\begin{abstract}
Objectives: ANSYS software has been used to predict temperature, stress, and heat flux distributions for dissimilar welding of MONEL 400 and AISI 304. Methods/Statistical Analysis: A total of twenty seven experiments have been performed for welding of MONEL 400 alloy and AISI 304 by using TIG welding process to find out the best possible welding parameters. The experiments conducted have been divided into three groups. In the first stage, second stage and third stage of experiments was conducted to study the welding process with AISI 304 filler rod, AISI 316 filler rod and MONEL 400 filler rod respectively. Findings: The developed stress is smaller at $350 \mathrm{amp}$ current, AISI 304 filler rod, and $3.6 \mathrm{~mm} / \mathrm{s}$ welding speed, which is noted as $0.31 \times 10^{-15} \mathrm{MPa}$. The optimum TIG welding parameter for stress was obtained as 150 amp current, AISI 304 filler rod, and $3.6 \mathrm{~mm} / \mathrm{s}$ welding speed. The mean value of generated temperature is higher at 350 amp current, AISI 316 filler rod, and $5.5 \mathrm{~mm} / \mathrm{s}$ welding speed, which is observed as $75671^{\circ} \mathrm{C}$. The optimum TIG welding parameters are $350 \mathrm{amp}$ input current, AISI 316 filler electrode, and $3.6 \mathrm{~mm} / \mathrm{s}$ welding speed for developed temperature. The optimum TIG welding parameter for heat flux was obtained as $350 \mathrm{amp}$ current, MONEL 400 filler rod, and $5.5 \mathrm{~mm} / \mathrm{s}$ welding speed. Application/Improvements: Dissimilar metal joints between MONEL 400 and AISI 304 are widely used in various applications fields like heat exchanger, chemical processing equipment etc.
\end{abstract}

Keywords: AISI 304, ANSYS Software, Dissimilar Metal Weld, MONEL 400 Alloy, TIG welding, Welding Simulation

\section{Introduction}

Monel-400 is the important nickel based alloy that contains about $60-70 \%$ nickel, $20-29 \%$ copper. Monel-400 is characterized by its good corrosion resistance, good weld ability and high strength. Therefore, it has many applications in chemical processing equipment, feed water heaters etc. Types 304 stainless steel is the most adaptable and commonly used due to corrosion oxidation resistance at low cost.

The analysis effect of residual stress on welded cantilever beam was simulated which has been welded by TIG welding process ${ }^{1}$. The developed residual stresses were relieved by heat treatment. The improvement in micro hardness properties and the ultimate tensile strength increases by $80 \mathrm{MPa}$ by inducing auxiliary vibrations into the weld pool during welding 2 . The effect of thermalstrain cycle on residual strains on corrosion-resistant austenitic steels of cylindrical shells was studied using TIG butt welds ${ }^{3}$. The surface alloying of AISI 304 stainless steel with titanium was carried out using the heat generated from the Gas Tungsten Arc (GTA) 4 . The micro hardness was increased from $267.5 \mathrm{HV}$ for the substrate to $2098 \mathrm{HV}$ for the surface alloyed layer. The dissimilar welding of INCONEL 625 and AISI 316 was studied by using 3D ANSYS 5 . The speed of the results is increased by $50 \%$, same $6 \%$ enhancement in X-displacement, $8 \%$ in $\mathrm{Z}$ displacement by using simulation ${ }^{6}$. Welding joints

*Author for correspondence 
between T91 and 304SS were developed using two welding consumables 308L and 309L by SMAW and GTAW respectively ${ }^{7}$. The average impact strength of the weldment prepared by GTAW technique is marginally more as compared to SMAW technique for all sections. The Gas Tungsten Arc Welding (GTAW) of blanks $2 \mathrm{~mm}$ thick of Duplex Stainless Steel (DSS) and Hot Rolled Medium and High Tensile Structural Steel (HRS) was carried out to investigate the metallurgical, mechanical properties and the fracture ${ }^{8}$. The SEM analysis indicates that the weldment possesses good tensile strength without decrease in ductility of the fusion zone. The variation of temperature in TIG welded SS 304 plate and compared measured data with simulation data, which have good agreement with the test data 9 . The Friction stir welding were used for the aluminum alloys and copper base alloys in which $\mathrm{ZrO} 2$ ceramic powder was used ${ }^{10}$. The maximum amount of hardness is about 160 Vickers which was obtained in four-pass mode and by using the powder, in compared with the base metal hardness which was about 80 Vickers.

MONEL 400 alloy and AISI 304 have widespread applications in various fields like marine and offshore environments. However, welding of MONEL 400 with AISI 304 is more difficult. The objective this experimental work is to investigate the weld ability of dissimilar weld, simulation of welding process and optimize welding parameters.

\section{Experimental Work}

Twenty-seven welded specimens have been prepared by using TIG welding process to find out the best possible welding parameters. The experiments conducted have been divided into three groups. In the first stage AISI 304 filler rod are used. AISI 316 filler rod and MONEL 400 filler rod are used in second and third stage of experiments respectively. The TIG welding process parameters which were used in this stage of experiments are shown in Table 1.

Table 1. Welding Parameters and Their Levels to be used in TIG welding

\begin{tabular}{|l|l|l|l|l|}
\hline \multirow{2}{*}{ S.No } & \multirow{2}{*}{ Input parameters } & \multicolumn{3}{|c|}{ Level } \\
\cline { 3 - 5 } & & $\mathbf{1}$ & $\mathbf{2}$ & \multicolumn{1}{|c|}{$\mathbf{3}$} \\
\hline 1. & $\begin{array}{l}\text { Welding Current } \\
\text { (Amps) }\end{array}$ & 150 & 250 & 350 \\
\hline 2. & Filler rod & AISI 304 & AISI 316 & $\begin{array}{l}\text { Monel } \\
400\end{array}$ \\
\hline 3. & $\begin{array}{l}\text { Welding Speed } \\
(\mathrm{mm} / \mathrm{sec})\end{array}$ & 3.5 & 5.5 & 6.8 \\
\hline
\end{tabular}

ANSYS Software is a CAE based simulation system designed to analyze various loading condition on various elements. In welding analysis, thermal simulation is used, first step is construction of geometry of workpiece and apply the boundary condition then sequentially simulate

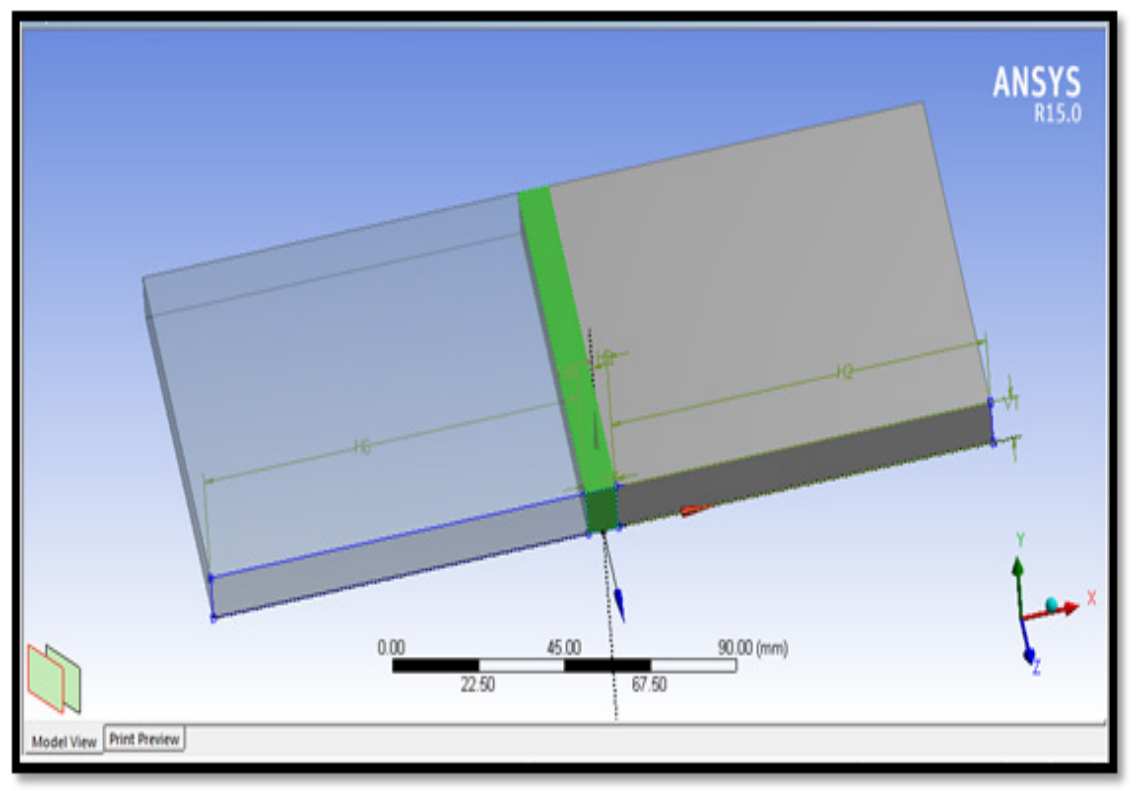

Figure 1. Sketch the geometry in ANSYS. 
the process. The sketch the geometry of the two workpiece for welding simulation is shown in Figure 1.

After sketching the workpiece and assigning the filler rod area, specify the unit system as 'SI', apply the conditions for welding, atmospheric temperature, welding speed. The mesh generation is shown in Figure 2.

Heat flow $=\mathrm{V} * \mathrm{c} /$ travel speed
Than after mesh generation apply the boundary condtions, like apply welding currents, welding travel speed, surface conditions etc. The welded zone is cool down by directly convection process through surface being contact with atmospheric air, so that simplified convection case is apply.

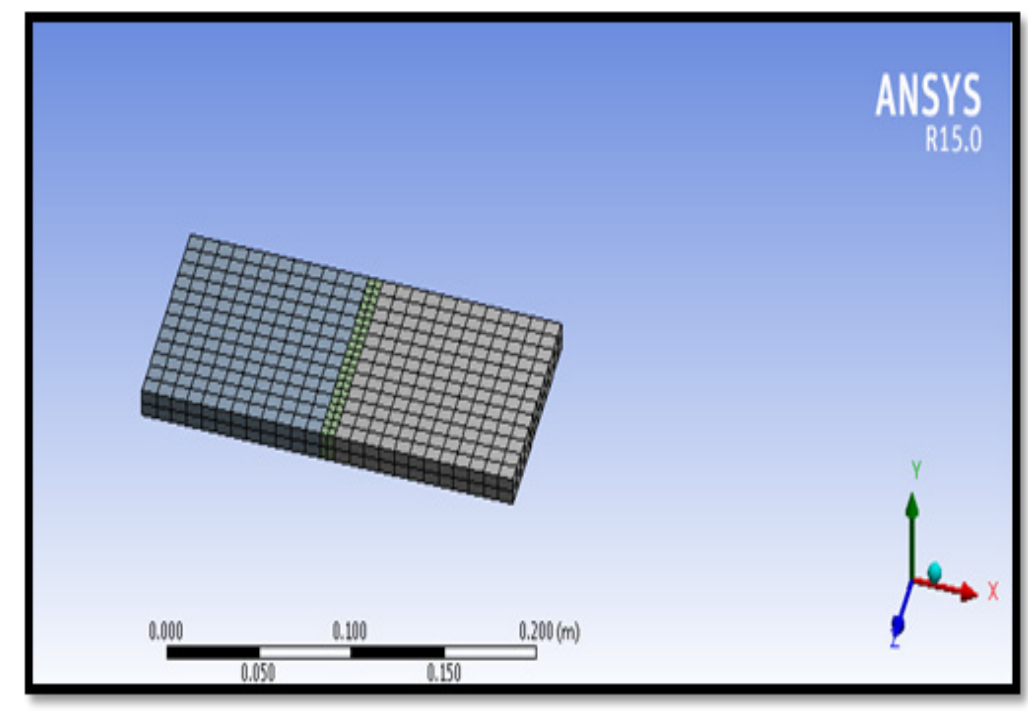

Figure 2. Mesh Generation in ANSYS.

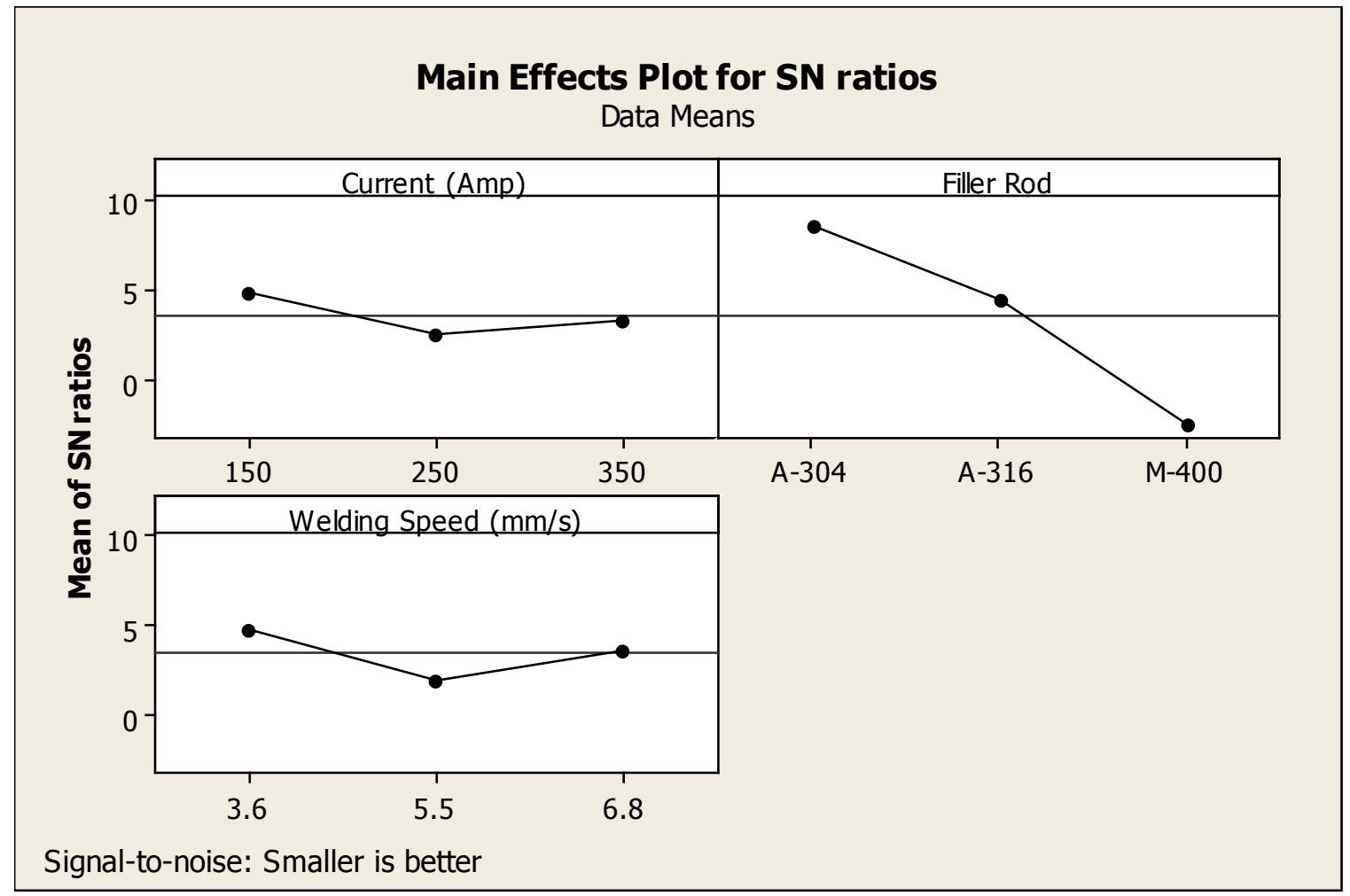

Figure 3. Effect of TIG welding on developed stress 


\section{Results and Discussion}

Experiments will be conduct based on Taguchi's method with three factors at three levels each. The results of stress which were measured after all the nine experiments perform in ANSYS Software. Now, after analyzing the experimental data from the test, the data is feed into the Minitab software for finding the optimum value from the parameters being taken in this experimentation.

From Figure 3, it is clear that the signal to noise ratio of developed stress is reduced by raising the current value. The signal to noise ratio of developed stress is lower at MONEL 400 filler rod. It is noticed that the signal to noise ratio of developed stress is declined by raising the welding speed.

Figure 4 shows interaction effect of welding parameters for stress generation during welding in ANSYS. It is clear that at $150 \mathrm{amp}$ current, the stress is increased by changing the filler rod from A-304 to A-316, and further changing the filler rod from A-316 to MONEL 400 filler rod, the developed stress is continuously increasing. The same type of trends is observed at 250 and $350 \mathrm{amp}$ currents by changing the filler rod from A-304 to A-316, and further changing the filler rod from A-316 to MONEL 400 filler rod the developed stress is continuously rises.
It is observed that at 150 amp current, the developed stress is reduced by raising the welding speed from 3.6 to $5.5 \mathrm{~mm} / \mathrm{s}$. By rising further welding speed from 5.5 to $6.8 \mathrm{~mm} / \mathrm{s}$, the developed stress is increased. At $250 \mathrm{amps}$ current, the stress is increased by increasing the welding speed from 3.6 to $5.5 \mathrm{~mm} / \mathrm{s}$ and further raise of welding speed from 5.5 to $6.8 \mathrm{~mm} / \mathrm{s}$, the developed stress is decreased. At $350 \mathrm{amp}$ current, the stress is increased by rising the welding speed from 3.6 to $5.5 \mathrm{~mm} / \mathrm{s}$ and further raise of welding speed from 5.5 to $6.8 \mathrm{~mm} / \mathrm{s}$, the developed stress is again increases.

It is noticed that by using A-304 filler rod, the stress is increased by increasing the welding speed from 3.6 to $5.5 \mathrm{~mm} / \mathrm{s}$. By increasing further welding speed from 5.5 to $6.8 \mathrm{~mm} / \mathrm{s}$, the developed stress again slightly increases. By using of A-316, the stress is increased by increasing the welding speed from 3.6 to $5.5 \mathrm{~mm} / \mathrm{s}$ and by raise of welding speed from 5.5 to $6.8 \mathrm{~mm} / \mathrm{s}$, the developed stress slightly decreases. By using of filler rod MONEL 400, the stress is increased by increasing the welding speed from 3.6 to $5.5 \mathrm{~mm} / \mathrm{s}$ and by raise of welding speed from 5.5 to $6.8 \mathrm{~mm} / \mathrm{s}$, the developed stress is decreased.

Figure 5 shows the effect of various welding parameters on the signal to noise ratio of temperature. It is clear that the signal to noise ratio of temperature is enhancing

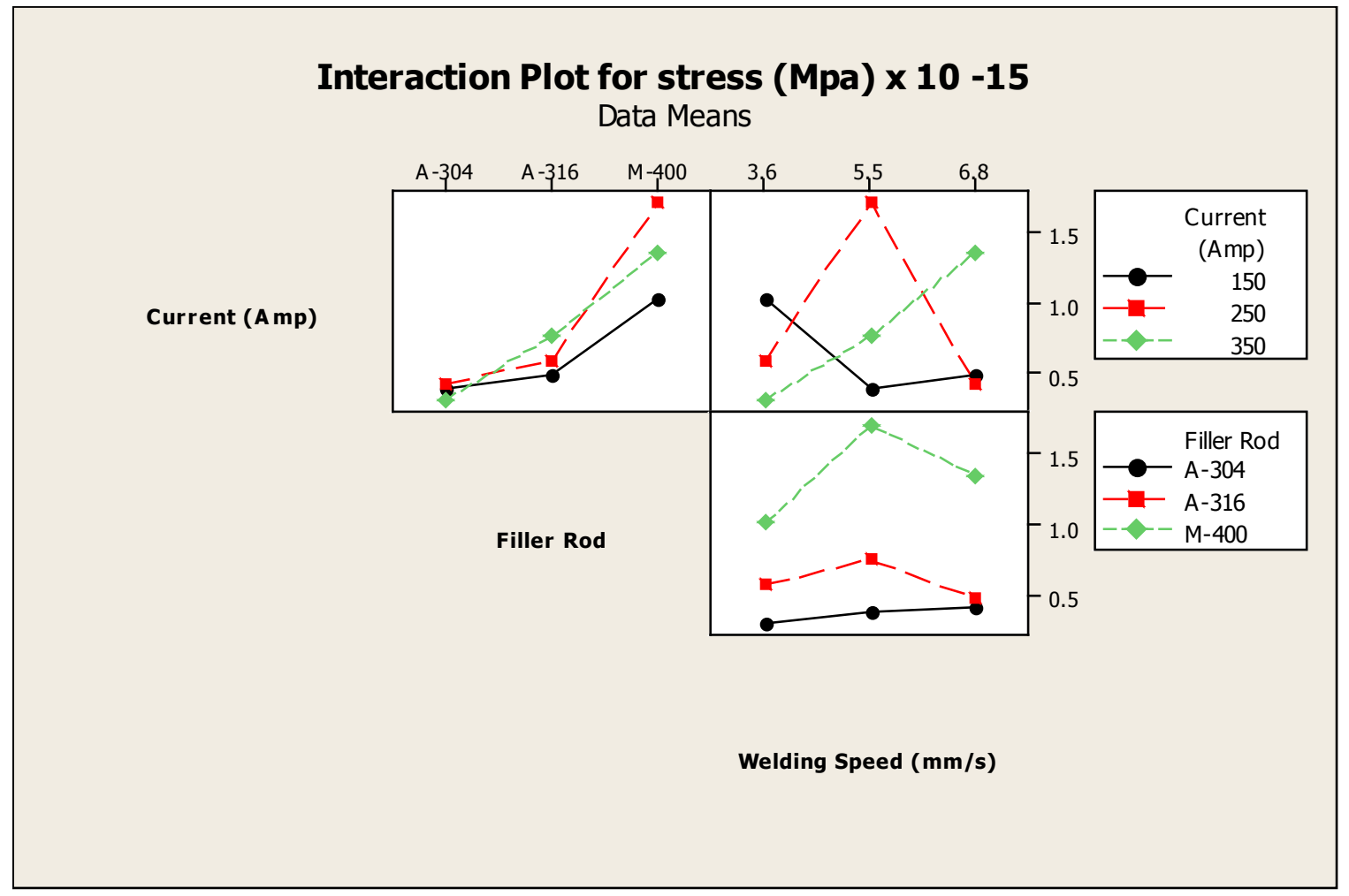

Figure 4. Interaction effect of welding parameters for developed stress. 


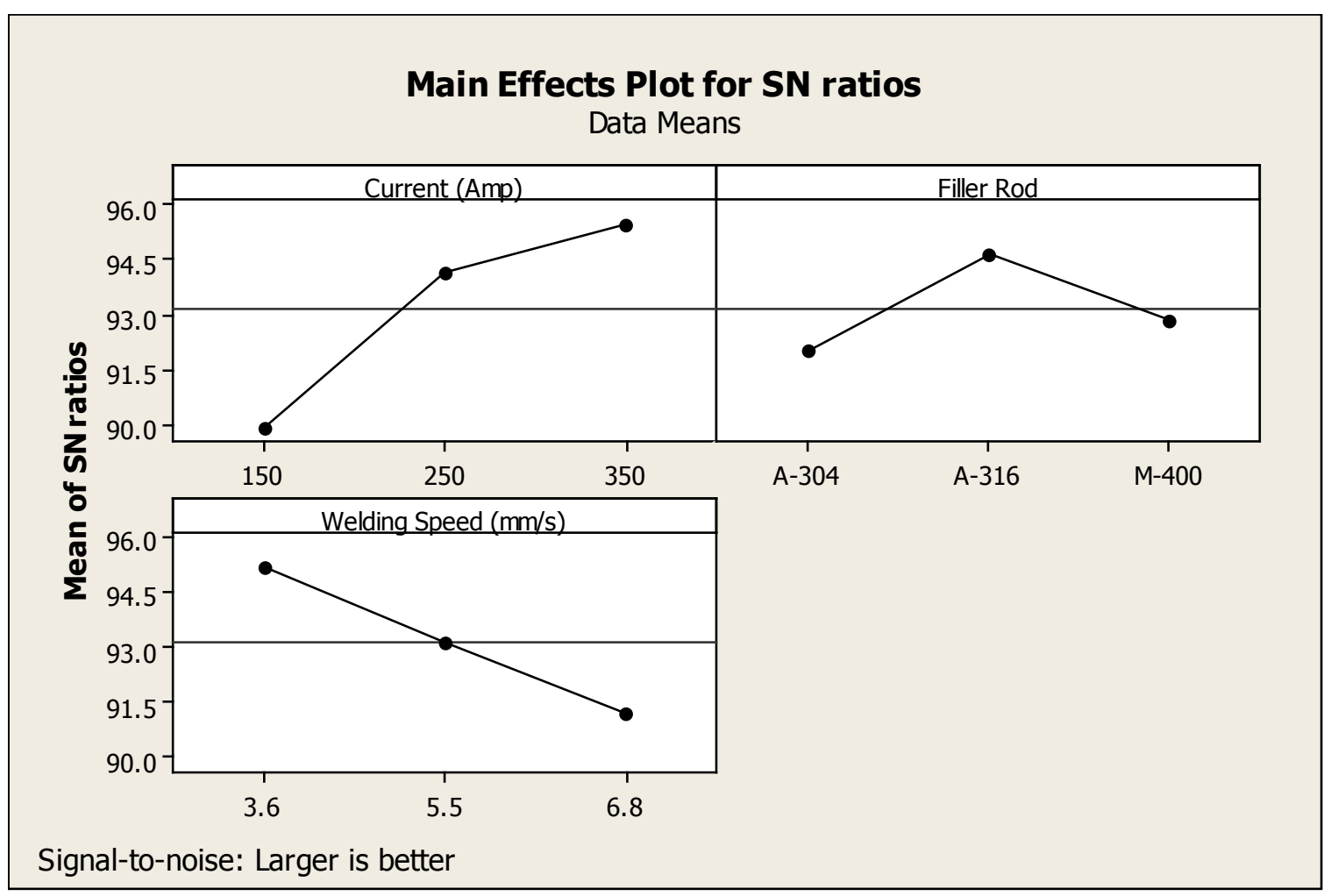

Figure 5. Effect of welding parameters on signal to noise ratio of temperature.

by raising the current. The mean of signal to noise ratio of temperature is increased by shifting the filler rod AISI316 instead of AISI 304. By using MONEL 400 filler rod, it is observed that the signal to noise ratio of temperature is reduced. It is observed that the signals to noise ratio of temperature rise by raising the welding speed.

Figure 6 shows interaction effect of TIG welding parameters for developed temperature generation during welding in ANSYS. It is clear that at $150 \mathrm{amp}$ current, the temperature slightly decreased by changing the filler rod from A-304 to A-316, and further changing the filler rod from A-316 to MONEL 400 filler rod, the developed temperature is increasing. At 250 amps current, the temperature is increase by changing the filler rod from A-304 to A-316, and further changing the filler rod from A-316 to MONEL 400 filler rod the developed temperature is decreasing. The same type of trends is observed at 350 amp currents by changing the filler rod from A-304 to A-316 (temperature increases), and further changing the filler rod from A-316 to MONEL 400 filler rod, the developed temperature is decreasing.

It is notice that at $150 \mathrm{amp}$ current, the developed temperature is reduced by raising the welding speed. At 250 amp current, the temperature is decreased by increasing the welding speed. At $350 \mathrm{amp}$ current, the temperature increased by raising the welding speed from 3.6 to 5.5 $\mathrm{mm} / \mathrm{s}$ and further rise of welding speed from 5.5 to 6.8 $\mathrm{mm} / \mathrm{s}$, the developed temperature decreases.

It is noticed that by using A-304 filler rod, the temperature decreases by increasing the welding speed from 3.6 to $5.5 \mathrm{~mm} / \mathrm{s}$. By increasing further welding speed from 5.5 to $6.8 \mathrm{~mm} / \mathrm{s}$, the developed temperature slightly increases. By using of A-316, the temperature decreased by increasing the welding speed from 3.6 to $5.5 \mathrm{~mm} / \mathrm{s}$ and by raise of welding speed from 5.5 to $6.8 \mathrm{~mm} / \mathrm{s}$, the developed temperature decreases. By using of filler rod MONEL 400, the temperature is increased by increasing the welding speed from 3.6 to $5.5 \mathrm{~mm} / \mathrm{s}$ and by raise of welding speed from 5.5 to $6.8 \mathrm{~mm} / \mathrm{s}$, the developed temperature slightly increases.

Figure 7 shows interaction effect of welding parameters for heat flux generation during welding in ANSYS. It is clear that at 150 amp current, the heat flux is decreased by changing the filler rod from A-304 to A-316, and further changing the filler rod from A-316 to MONEL 400 filler rod the developed heat flux is increased. At $250 \mathrm{amp}$ cur- 


\section{Interaction Plot for Temperature (OC)}

Data Means

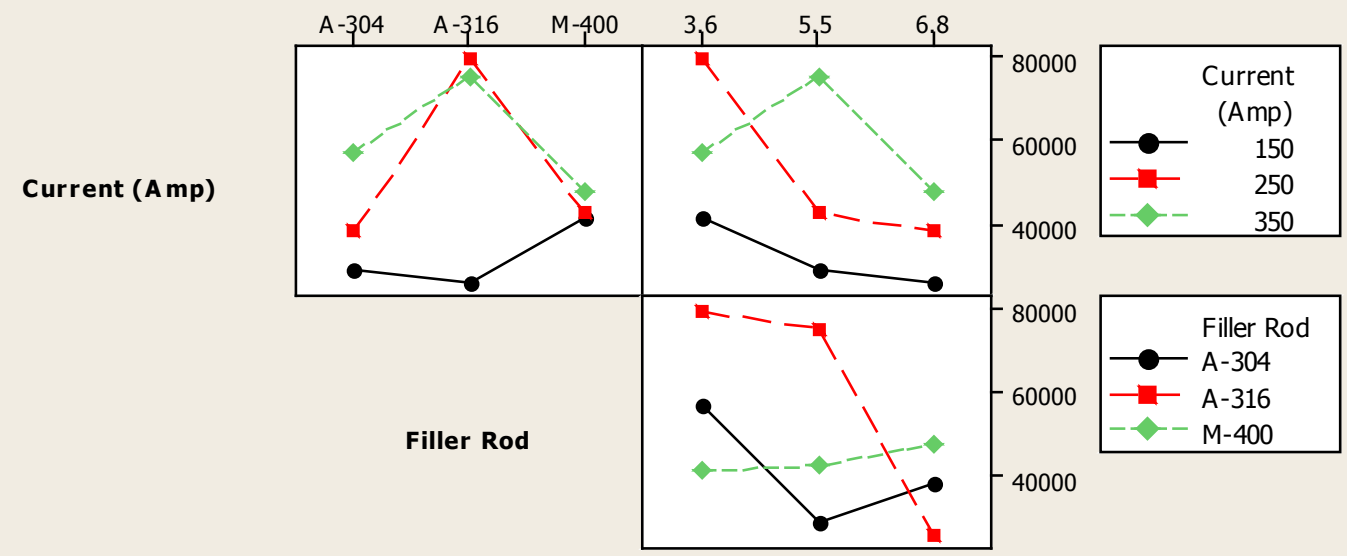

Welding Speed $(\mathrm{mm} / \mathrm{s})$

Figure 6. Interaction effect of welding parameters for developed temperature.

\section{Interaction Plot for Heat Flux (KW/ mm2)}

Data Means

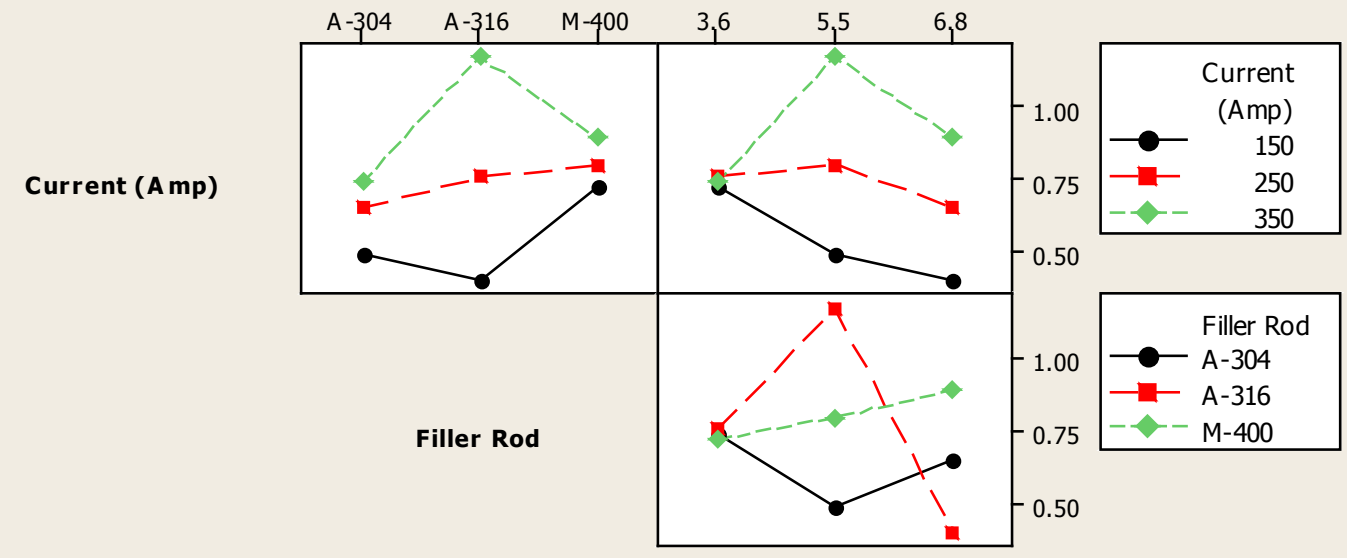

Welding Speed $(\mathrm{mm} / \mathrm{s})$

Figure 7. Interaction effect of welding parameters for developed heat flux. 
rent, the heat flux is increased by changing the filler rod from A-304 to A-316, and further changing the filler rod from A-316 to MONEL 400 filler rod the developed heat flux again increased. At $350 \mathrm{amp}$ currents by changing the filler rod from A-304 to A-316 heat flux is increased, and further changing the filler rod from A-316 to MONEL 400 filler rod the developed heat flux is decreasing.

It is observed that at $150 \mathrm{amp}$ current, the heat flux is reduced by raising the welding speed. At $250 \mathrm{amps}$ current, the heat flux slightly enlarges by increasing the welding speed from 3.6 to $5.5 \mathrm{~mm} / \mathrm{s}$ and further raise of welding speed from 5.5 to $6.8 \mathrm{~mm} / \mathrm{s}$, the developed heat flux is decreased. At 350 amps current, the heat flux is increased by increasing the welding speed from 3.6 to 5.5 $\mathrm{mm} / \mathrm{s}$ and by enlarging of welding speed from 5.5 to 6.8 $\mathrm{mm} / \mathrm{s}$, the developed heat flux is decreased.

It is noticed that by using A-304 filler rod, the heat flux is decreased by increasing the welding speed from 3.6 to $5.5 \mathrm{~mm} / \mathrm{s}$. By increasing further welding speed from 5.5 to $6.8 \mathrm{~mm} / \mathrm{s}$, the developed heat flux slightly increases. By using of A-316, the heat flux is increased by increasing the welding speed from 3.6 to $5.5 \mathrm{~mm} / \mathrm{s}$ and by rising of welding speed from 5.5 to $6.8 \mathrm{~mm} / \mathrm{s}$, the heat flux is reduced. At filler rod MONEL 400, the heat flux increased by raising the welding speed from 3.6 to $5.5 \mathrm{~mm} / \mathrm{s}$ and by enlarging of welding speed from 5.5 to $6.8 \mathrm{~mm} / \mathrm{s}$, the developed heat flux again increases.

\section{Conclusions}

A thermal simulation model of welding is presented with help of ANSYS software. The developed model is able to predict temperature, stress, and heat flux distributions. The followings are concluded from analysis:

1. The mean value of developed stress is smaller at 350 amp current, AISI 304 filler rod, and $3.6 \mathrm{~mm} / \mathrm{s}$ welding speed which is noted as $0.31 \times 10-15 \mathrm{MPa}$.

2. The optimum TIG welding parameters for stress was obtained as $150 \mathrm{amp}$ current, AISI 304 filler rod, and $3.6 \mathrm{~mm} / \mathrm{s}$ welding speed.

3. The mean value of generated temperature is higher at $350 \mathrm{amp}$ current, AISI 316 filler rod, and $5.5 \mathrm{~mm} / \mathrm{s}$ welding speed which is observed as $756.71^{\circ} \mathrm{C}$.
4. The optimum TIG welding parameters for temperature was obtained as $350 \mathrm{amp}$ current, AISI 316 filler rod, and $3.6 \mathrm{~mm} / \mathrm{s}$ welding speed.

5. The mean value of generated heat flux is higher at 350 amp current, AISI 316 filler rod, and $5.5 \mathrm{~mm} / \mathrm{s}$ welding speed which is observed as $1.175 \mathrm{KW} / \mathrm{mm}^{2}$.

6. The optimum TIG welding parameters for heat flux was obtained as $350 \mathrm{amp}$ current, MONEL 400 filler rod, and $5.5 \mathrm{~mm} / \mathrm{s}$ welding speed.

\section{References}

1. Vaisak V, Jason C, Issac J, Varghese VM. Effect of welding residual stress on natural frequency of structures. International Journal of Innovative Research in Advanced Engineering. 2014; 1(10):459-62.

2. Singh PK, Patel D, Prasad SB. Development of vibratory welding technique and tensile properties investigation of shielded metal arc welded joints. Indian Journal of Science and Technology. 2016; 9(35):1-6. https://doi.org/10.17485/ijst/2016/v9i35/92846.

3. Atroshenko A, Vairis A, Bichkov V, Nikiforov R. ANSYS Simulation of residual strains in butt-welded joints. Journal of Engineering Science and Technology Review, Special Issue on Simulation of Manufacturing Technologies. 2014; 7(5):9-11. https://doi.org/10.25103/jestr.075.03.

4. Narayanan V, Sellamuthu R, Saravanan R. An investigation on the hardness and wear rate of surface alloyed AISI304 stainless steel with Ti using GTA as Heat Source. Indian Journal of Science and Technology. 2016; 9(34):1-6. https:// doi.org/10.17485/ijst/2016/v9i34/100946.

5. Andrea C, Paolo F. Multipurpose ANSYS FE procedure for welding processes simulation. Fusion Engineering and Design. 2009; 84(2):546-53. https://doi.org/10.1016/j. fusengdes.2009.01.039

6. Gohel V, Makwana J, Ranjan RK. Thermo-mechanical analysis in TIG welding of S.S 304. International Journal of Engineering Development and Research. 2016; 4(2):1704-10.

7. Dhaliwal NPS, Mittal R, Gill S, Khullar P. Comparative evaluation of impact strength of dissimilar metal weld between T91 and 304SS prepared by SMAW and GTAW techniques. Indian Journal of Science and Technology. 2016; 9(39):1-6. https://doi.org/10.17485/ijst/2016/v9i39/101403.

8. Devakumar D, Jabaraj DB, Raja VKB, Jayaprakash J. Experimental investigation of DSS/HRS GTAW weldments. Indian Journal of Science and Technology. 2016; 9(43):1-6. https://doi.org/10.17485/ijst/2016/v9i43/101986. 
9. Harshal BS, Eknath RD. Finite element model for the effect of heat input and speed on residual stress during welding. International Journal of Mechanical Engineering and Research. 2014; 3(3):763-76.
10. Beglarzadeh B, Davoodi B. Study the microstructures of nano-composite copper/zirconium dioxide under the PROCESS of FSW (Friction Stir Welding). Indian Journal of Science and Technology. 2015; 8(35):1-11. https://doi.org/10.17485/ijst/2015/v8i35/87108 